\title{
Spatio-Temporal Model of Rainfall Data Using Kalman Filter and Expectation-Maximization Algorithm
}

\author{
MODEL SPATIO TEMPORAL DATA CURAH HUJAN \\ MENGGUNAKAN KALMAN FILTER DAN ALGORITMA \\ EKSPEKTASI-MAKSIMISASI
}

\author{
Muh. Idil Islami*1, Amran Rahim ${ }^{* 2}$, A. Kresna Jaya ${ }^{3}$, Bambang Bakri ${ }^{4}$
}

\begin{abstract}
Location and time dimension data modeling, also known as spatial-temporal data, generally has high complexity. This study analyzes a spatial-temporal model of rainfall data and climate variables, namely temperature, and humidity. The complexity of the relationship between variables and parameters in the spatial-temporal model is simplified by a hierarchical approach. The parameter estimation of the ratiotemporal model uses the Kalman Filter approaches and the Expectation-Maximization (EM) method combined with the bootstrap method to calculate the standard error estimation. Implementation of the spatial-temporal model on rainfall data in South Sulawesi Province with temperature and humidity shows that there is a relationship between rainfall and temperature and humidity.
\end{abstract}

Keywords: Bootstrap Method, Expectation-Maximization Algorithm, Kalman Filter, Rainfall, Spatial-Temporal Model.

\begin{abstract}
Abstrak
Pemodelan data berdimensi lokasi dan waktu atau dikenal sebagai data spasial-temporal, umumnya memiliki kompleksitas yang tinggi. Penelitian ini menganalisis pola data curah hujan menggunakan model spasial-temporal dan hubungannya dengan variable iklim yakni temperatur dan kelembaban. Kompleksitas hubungan antara variabel dan parameter dalam model spasial-temporal disederhanakan dengan pendekatan hierarki. Estimasi parameter model spasio-temporal menggunakan pendekatan Kalaman Filter dan metode Ekspektasi-Maksimisasi (EM) yang dikombinasikan dengan metode bootstrap untuk menghitung standar eror penaksiran parameter. Implementasi model spasial-temporal pada data curah hujan di Provinsi Sulawesi Selatan dengan kovariat temperatur dan kelembaban udara menunjukkan bahwa terdapat hubungan antara curah hujan dengan temperatur dan kelembaban.
\end{abstract}

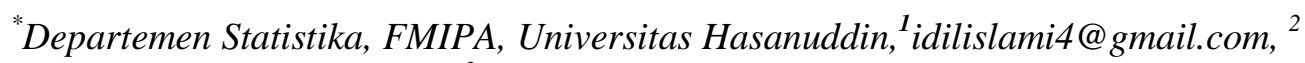
amran@science.unhas.ac.id, ${ }^{3}$ andikresna.jaya@gmail.com **Departemen Teknik Sipil, Fakultas Teknik, Universitas Hasanuddin, ${ }^{4}$ bambangbakri@gmail.com

This work is licensed under a Creative Commons Attribution-NonCommercial 4.0 International License 


\section{Muh. Idil Islami, Amran Rahim, A. Kresna Jaya, Bambang Bakri Jurnal Matematika, Statistika $\mathcal{E}$ Komputasi}

Kata Kunci: Algoritma Ekspektasi-Maksimisasi, Curah hujan, Kalman Filter, Metode Bootstrap Model Spasial-Temporal.

\section{PENDAHULUAN}

Pola curah hujan sangat penting peranannya dalam kegiatan sosial-ekonomi masyarakat. Informasi pola curah hujan dapat digunakan untuk menentukan waktu pelaksanaan kegiatan sosialekonomi yang dapat memberikan keuntungan dan mencegah kerugian yang mungkin terjadi. Oleh karena itu, pemahaman tentang pola curah hujan diperlukan dalam rangka untuk mengoptimalkan kegiatan sosial-ekonomi masyarakat [1]. Pola curah hujan dapat dinyatakan dalam model spasial maupun model temporal atau model spasial dan temporal.

Model Spatio-Temporal (ST) adalah model yang merepresentasikan fenomena alam yang diobservasi dalam dimensi spasial dan temporal [4]. Analisis datanya mempertimbangkan dependensi spasial antar wilayah pengamatan dan korelasi satu atau beberapa lag waktu. Observasi secara temporal memiliki kecenderungan yang tidak independen tapi membentuk sebuah runtun waktu. Model ST mulai dikembangkan oleh Bilonick \& Nicholas pada tahun 1983 yang meneliti data curah hujan dengan 3 pendekatan yang berbeda yaitu, pertama fokus pada efek temporal dengan mengabaikan efek spasial, kedua fokus pada efek spasial dengan mengabaikan efek temporal dan analisis spasial temporal [10].

\section{TINJAUAN PUSTAKA}

\subsection{Data Spasial}

Analisis data geostatistika dilakukan untuk menaksis nilai peubah di suatu lokasi yang belum diobservasi $\left(s_{0}\right)$. Nilai dari suatu variabel yang diamati dapat dinyatakan sebagai peubah acak spasial $Z\left(s_{i}\right) ; i=1, \ldots, n$ dengan $s$ merupakan vektor lokasi [12]. Misalkan peubah acak $X$ didefinisikan sebagai peubah acak spasial $Z(s)$ di lokasi $s$ dan peubah acak $Y$ didefinisikan sebagai peubah acak spasial $Z(s+h)$ di lokasi $s+h$ dengan $h$ merupakan jarak antara $X$ dan $Y$. Jika $h$ mendekati nol maka pengaruh antara $X$ dan $Y$ semakin kuat dan jika $h$ membesar maka pengaruh $X$ dan $Y$ semakin lemah.

\subsection{Stasioner}

Kestasioneran data dapat diuji menggunakan uji Augmented Dickley-Fuller (ADF). Uji ADF dilakukan untuk mengetahui adanya akar unit. Jika data stasioner maka tidak terdapat akar unit, maupun sebaliknya. Langkah-langkah uji ADF, adalah sebagai berikut:

1. Hipotesis

$H_{0}: \delta=0$ (data time series tidak stasioner)

$H_{1}: \delta \neq 0$ (data time series stasioner)

2. Statistik uji

$$
\tau_{\delta}=\frac{\hat{\delta}}{(S E(\hat{\delta}))}
$$

3. Kriteria pengujian

Tolak $H_{0}$ jika $\left|\tau_{\delta}\right| \geq\left|\tau_{n, \alpha}\right|$ Dickley-Fuller, dengan $\delta$ adalah parameter yang ditaksir, $n$ adalah jumlah data, $\alpha$ adalah taraf signifikan dan $\tau$ adalah konstanta [9]. 


\section{Muh. Idil Islami, Amran Rahim, A. Kresna Jaya, Bambang Bakri Jurnal Matematika, Statistika $\mathcal{E}$ Komputasi}

\subsection{Indeks Moran}

Perhitungan autokorelasi spasial menggunakan Indeks Moran dengan matriks pembobot $\boldsymbol{W}$ berdasarkan perkalian silang adalah (Banerjee, 2004):

$$
I=\frac{n \sum_{i} \sum_{j} w_{i j}\left(y_{i}-\bar{y}\right)\left(y_{j}-\bar{y}\right)}{\sum_{i \neq j} w_{i j} \sum_{i}\left(y_{i}-\bar{y}\right)^{2}}
$$

Langkah pengujian menggunakan Indeks Moran adalah sebagai berikut :

1. Hipotesis

$H_{0}: I=0$ (tidak ada autokorelasi antar lokasi)

$H_{1}: I \neq 0$ (ada autokorelasi antar lokasi)

2. Statistik uji

dimana:

$$
Z(I)=\frac{I-E(I)}{\sqrt{\operatorname{Var}(I)}}
$$

$$
\begin{aligned}
E(I) & =I_{0} \\
& =-\frac{1}{1-n} ; \quad n \text { adalah banyaknya lokasi pengamatan } \\
\operatorname{Var}(I) & =\frac{n^{2} S_{1}-n S_{2}+3 S_{0}^{2}}{\left(n^{2}-1\right) S_{0}^{2}}-[E(I)]^{2} \\
S_{0} & =\sum_{i=1}^{n} \sum_{j=1}^{n} w_{i j} \\
S_{1} & =\frac{1}{2} \sum_{i=1}^{n} \sum_{j=1}^{n}\left(w_{i j}+w_{j i}\right)^{2} \\
S_{2} & =\sum_{i=1}^{n}\left(\sum_{j=1}^{n} w_{i j}+\sum_{j=1}^{n} w_{j i}\right)^{2}
\end{aligned}
$$

3. Kriteria pengujian

Apabila $|E(I)|>Z_{1-\alpha}$ maka $H_{0}$ ditolak. $Z_{1-\alpha}$ diperoleh dari tabel distribusi normal [16].

\subsection{Proses Markov}

Proses Markov merupakan fenomena dimana kejadian masa datang hanya dipengaruhi oleh masa sekarang dan tidak dipengaruhi masa lalu [17].

$$
\mathrm{P}\left(X_{t+1} \mid X_{t}, X_{t-1}, X_{t-2}, \ldots, X_{1}\right)=\mathrm{P}\left(X_{t+1} \mid X_{t}\right)
$$

\subsection{Model Spatio-Temporal}

Model Spatio-Temporal yang digunakan dalam penelitian ini mengadopsi model yang diteliti oleh Fassò and Cameletti di tahun 2017 [8]. Misalkan $Z(s, t)$ adalah proses SpatioTemporal yang diamati pada waktu $t$ di lokasi $s$ dan $Z_{t}=\left\{Z\left(s_{1}, t\right), \ldots, Z\left(s_{n}, t\right)\right\}$ merupakan dataset pada waktu $t$ sebanyak $n$ lokasi $s_{1}, \ldots, s_{n}$. Misalkan $Y_{t}=\left\{Y_{1}(t), \ldots, Y_{p}(t)\right\}$ adalah vektor berdimensi $p$ dari proses temporal yang tidak terobservasi pada waktu $t$ dengan $p \leq n$. Prosedur penaksiran parameter untuk $t=1, \ldots, T$ dilakukan tiga tahap sebagai berikut $[5,6]$ : 


\section{Muh. Idil Islami, Amran Rahim, A. Kresna Jaya, Bambang Bakri Jurnal Matematika, Statistika E Komputasi}

dimana,

$$
\boldsymbol{Z}_{t}=\boldsymbol{U}_{t}+\varepsilon_{t}
$$

$\boldsymbol{U}_{t}$ : Proses Spatio-Temporal yang tidak teramati

$\varepsilon_{t}$ : Galat pengukuran.

Proses $\boldsymbol{U}_{t}$ dipengaruhi oleh kovariat dan proses temporal laten sebagai berikut:

dimana,

$$
\boldsymbol{U}_{t}=\boldsymbol{X}_{t} \beta+\boldsymbol{K} \boldsymbol{Y}_{t}+\omega_{t}
$$

$\boldsymbol{X}_{t}$ ialah matriks kovariat yang diamati pada waktu $t$ di lokasi $n$

$\boldsymbol{\beta}$ ialah parameter model regresi

$\boldsymbol{Y}_{t}$ ialah proses latent temporal dengan lokasi tetap

$\boldsymbol{K}$ ialah matriks pembobot dari $Y_{t}$ untuk setiap lokasi spasial $s_{i}, i=1, \ldots, n$

$\omega_{t}$ ialah galat model

Proses temporal laten diasumsikan bergantung pada proses laten satu lag sebelumnya ditambah dengan galat inovasi sebagai berikut:

dimana,

$$
\boldsymbol{Y}_{t}=\boldsymbol{G} \boldsymbol{Y}_{t-1}+\eta_{t}
$$

$\boldsymbol{Y}_{t}$ ialah proses autoregressive berdimensi $p$

$G$ ialah matriks transisi

$\eta_{t}$ ialah galat inovasi

\subsection{Algoritma Ekspektasi-Maksimasi (EM)}

Algoritma EM bekerja dengan mendapatkan MLE dari marjinal likelihood, secara iteratif menerapkan dua tahap berikut $[2,13]$ :

1. Tahap-E

Menghitung nilai ekspektasi bersyarat dari fungsi log-likelihood, sehubungan dengan distribusi bersyarat dari $\boldsymbol{Y}_{t}$ jika diketahui $\boldsymbol{Z}_{t}$ dibawah estimasi parameter saat ini $\boldsymbol{\Psi}^{(k)}$, didefinisikan sebagai berikut:

2. Tahap-M

$$
Q\left(\boldsymbol{\Psi} \mid \boldsymbol{\Psi}^{(k)}\right)=E\left[\ln L\left(\boldsymbol{\Psi} ; \mathbf{z}_{t}, \boldsymbol{y}_{t}\right) \mid \mathbf{z}_{t}, \boldsymbol{\Psi}^{(g)}\right]
$$

Tahap-M menemukan parameter yang memaksimalkan kuantitas di bawah ini:

$$
\boldsymbol{\Psi}^{(k+1)}=\underset{\boldsymbol{\Psi}}{\operatorname{argmax}} Q\left(\boldsymbol{\Psi} \mid \Psi^{(k)}\right)
$$

\subsection{Metode Bootstrap}

Misalkan peubah acak $x_{i}, i=1,2, \ldots, n$ memiliki peluang $1 / n$ untuk setiap $x_{i}$ dengan distribusi empirik $F$. Sampel bootstrap didefinisikan sebagai sampel acak dengan ukuran $n$ yang diambil dari $F$, sehingga diperoleh $\mathbf{x}^{\star}=\left(x_{1}^{\star}, x_{2^{\star}}, \ldots, x_{n}^{\star}\right)$. Notasi $\star$ pada $\mathbf{X}^{\star}$ menyatakan versi resample dari peubah acak $\mathbf{x}$. Data bootstrap $x_{1}{ }^{\star}, x_{2}{ }^{\star}, \ldots, x_{n^{\star}}$, dapat dikatakan sebagai sampel acak dengan ukuran $n$ yang diambil dengan pengembalian dari sebuah populasi sebanyak $n$ objek $\mathbf{x}=\left(x_{1}, x_{2}, \ldots, x_{n}\right)[8]$. 


\section{Muh. Idil Islami, Amran Rahim, A. Kresna Jaya, Bambang Bakri Jurnal Matematika, Statistika $\mathcal{E}$ Komputasi}

\section{METODE PENELITIAN}

\subsection{Sumber Data}

Data yang digunakan dalam penelitian ini merupakan data cuaca yang dikumpulkan melalui satelit di 24 titik di Sulawesi Selatan (Gambar 1) dengan koordinat Longitude ialah $119.375^{\circ}$ sampai dengan $-120.312^{\circ}$ dan Latitude ialah $-3.902^{\circ}$ sampai dengan $-5.464^{\circ}$, yang diperoleh dari NOAA (National Oceanic and Atmospheric Administration) melalui alamat website berikut: (https://www.avl.class.noaa.gov/saa/products/catSearch)

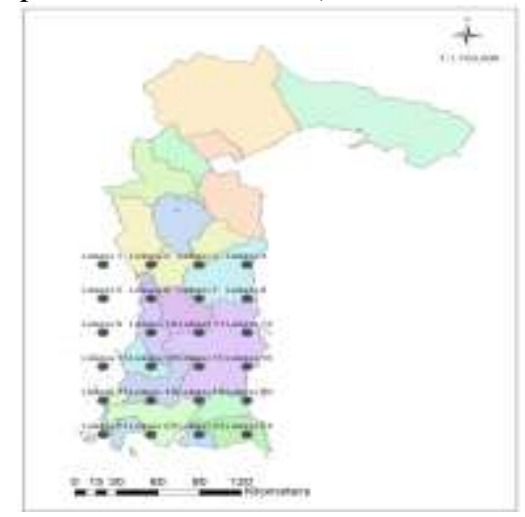

Gambar 1: Lokasi pengukuran data curah hujan

\subsection{Identifikasi Peubah}

Peubah-peubah yang digunakan dalam penelitian ini sebagai berikut:

a. Peubah respon, yaitu pengukuran curah hujan di beberapa titik di Sulawesi Selatan $\left(Z_{t}\right)$.

b. Peubah prediktor (kovariat), yang terdiri dari:

1. Peubah prediktor, yaitu suhu rata-rata lokasi pengamatan $\left(X_{1}\right)$ dan kelembaban lokasi pengamatan $\left(X_{2}\right)$.

2. Peubah prediktor, koordinat lokasi pengamatan Longitude dan Latitude.

\subsection{Tahap-Tahap Penelitian}

1. Menentukan estimator parameter maximum likelihood menggunakan algoritma EM dan Kalman filter

a. Tahap-E

Menghitung nilai ekspektasi bersyarat dari fungsi log-likelihood, sehubungan dengan distribusi bersyarat dari $\boldsymbol{Y}_{t}$ jika diketahui $\boldsymbol{Z}_{t}$ dibawah estimasi parameter saat ini $\boldsymbol{\theta}^{(k)}$, didefinisikan sebagai berikut:

$$
Q\left(\boldsymbol{\Psi} \mid \boldsymbol{\Psi}^{(k)}\right)=E\left[\ln L\left(\boldsymbol{\Psi} ; \boldsymbol{z}_{t}, \boldsymbol{y}_{t}\right) \mid \mathbf{z}_{t}, \boldsymbol{\Psi}^{(g)}\right]
$$

b. Tahap-M

Tahap-M menemukan parameter yang memaksimumkan persamaan berikut:

$$
\boldsymbol{\Psi}^{(g+1)}=\underset{\boldsymbol{\theta}}{\operatorname{argmax}} Q\left(\boldsymbol{\Psi} \mid \boldsymbol{\Psi}^{(g)}\right)
$$

2. Menentukan intensitas curah hujan perbulan di setiap lokasi pada setiap tahun pengamatan

3. Simulasikan data observasi

4. Melakukan uji stasioner data di setiap titik lokasi

5. Melakukan uji korelasi spasial 


\section{Muh. Idil Islami, Amran Rahim, A. Kresna Jaya, Bambang Bakri Jurnal Matematika, Statistika \& Komputasi}

6. Menentukan fungsi likelihood

7. Melakukan pengujian normalitas menggunakan uji Shapiro-Wilk.

\section{HASIL UTAMA}

Untuk membahas hasil yang dicapai dalam paper ini, terlebih dahulu diuraikan tentang Model ST dengan pendekatan metode Kalman Filter. Pada uraian ini ditunjukkan parameter model yang digunakan serta pembahasan tentang hasil penaksirannya menggunakan algoritma EM.

\subsection{Metode Kalman}

Estimasi state $\boldsymbol{y}_{t}(t=1, \ldots, T)$ dan parameter dari suatu state pada waktu $t$ dengan data pengukuran sampai waktu ke $r$ didefinisikan sebagai $\mathbf{z}^{r}=\left\{\mathbf{z}_{1}, \ldots, \mathbf{z}_{r}\right\}$ diperoleh melalui algoritma kalman filter dan proses smoother. Untuk $r=t$ terjadi proses filtering, $r<t$ proses prediksi, dan $r>t$ proses smooth pada state $[14,15]$. Nilai peluang bersyarat

$$
p\left(\boldsymbol{y}_{t} \mid \mathbf{z}^{r}\right)
$$

memuat semua informasi mengenai state $\boldsymbol{y}_{t}$ pada waktu $t$ diberikan data pengamatan sampai waktu ke-r. Peluang bersyarat dalam persamaan (4.1) diasumsikan berdistribusi Gaussian, sehingga parameter yang diestimasi adalah mean dan covariance. Tahap pemodelan adalah sebagai berikut:

1. Proses filtering

$$
\begin{aligned}
& \widehat{\boldsymbol{y}}_{t}^{t}=\widehat{\boldsymbol{y}}_{t}^{t-1}+\mathbf{A}_{t}\left(\mathbf{z}_{t}-\mathbf{x}_{t} \beta-\mathbf{K} \hat{\boldsymbol{y}}_{t}^{t-1}\right) \\
& \mathbf{P}_{t}^{t}=\left(\mathbf{I}-\mathbf{A}_{t} \mathbf{K}\right) \mathbf{P}_{t}^{t-1}\left(\mathbf{I}-\mathbf{A}_{t} \mathbf{K}\right)^{\prime}-\mathbf{A}_{t} \boldsymbol{\Sigma}_{e} \mathbf{A}_{t}^{\prime} \\
& \text { dimana, } \mathbf{A}_{t}=\mathbf{P}_{t}^{t-1} \mathbf{K}^{\prime}\left(\boldsymbol{\Sigma}_{e}+\mathbf{K} \mathbf{P}_{t}^{t-1} \mathbf{K}^{\prime}\right)^{-1} \text { merupakan Kalman gain }
\end{aligned}
$$

2. Tahap smothering menggunakan persamaan berikut:

$$
\begin{aligned}
& \widehat{\boldsymbol{y}}_{t-1}^{r}=\widehat{\boldsymbol{y}}_{t-1}^{t-1}+\mathbf{B}_{t-1}\left(\widehat{\boldsymbol{y}}_{t}^{r}-\widehat{\boldsymbol{y}}_{t}^{t-1}\right) \\
& \mathbf{P}_{t-1}^{r}=\mathbf{P}_{t-1}^{t-1}+\mathbf{B}_{t-1}\left(\mathbf{P}_{t}^{r}-\mathbf{P}_{t}^{t-1}\right) \mathbf{B}_{t-1}^{\prime}
\end{aligned}
$$

\subsection{Hasil Estimasi Model ST}

Hasil estimasi menggunakan metode Kalman dan algoritma EM menggunakan hasil metode bootstrap untuk membangkitkan sampel dari parameter hasil estimasi sebanyak 400 kali dan menguji distribusinya menggunakan uji Shapiro-Wilk. Proses bootsrap juga menghasilkan Standar deviasi residual masing-masing parameter. Prosedur bootstrap, uji Shapiro-Wilk, dan standar deviasi residual masing-masing dilakukan menggunakan bantuan RStudio Versi 1.1.456 yang hasilnya ditampilkan pada Tabel 1.

Nilai estimasi parameter $\beta_{0}$ dalam Tabel 1 menunjukkan bahwa intensitas hujan rata-rata ialah sebesar 3,66 $\mathrm{mm}$ tanpa adanya pengaruh dari besaran faktor suhu rata-rata $\left(\beta_{1}\right)$ dan kelembaban udara $\left(\beta_{2}\right)$ berdasarkan model ST yang digunakan. Umumnya interpretasi hasil estimasi berkaitan dengan nilai estimasi parameter suhu rata-rata dan kelembaban udara.

Nilai estimasi suhu rata-rata menunjukkan adanya peningkatan instensitas hujan di suatu lokasi seiring dengan meningkatnya suhu di lokasi tersebut. Hal ini terjadi karena pada lokasi dengan suhu yang tinggi membuat pergerakan angin banyak menuju daerah tersebut. Pergerakan angin ke daerah yang bersuhu tinggi dapat membawa kumpulan awan yang menyebabkan intensitas curah hujan di daerah tersebut menjadi meningkat. 
Muh. Idil Islami, Amran Rahim, A. Kresna Jaya, Bambang Bakri Jurnal Matematika, Statistika \& Komputasi

Tabel 1: P-value uji Shapiro-Wilk, standar deviasi residual, dan interval kepercayaan

\begin{tabular}{cccccc}
\hline Parameter & $\begin{array}{c}\text { Nilai } \\
\text { Estimasi }\end{array}$ & p-value & $\begin{array}{c}\text { Standar } \\
\text { Deviasi } \\
\text { residual }\end{array}$ & $\begin{array}{c}\text { Batas } \\
\text { Bawah }\end{array}$ & $\begin{array}{c}\text { Batas } \\
\text { Atas }\end{array}$ \\
\hline$\beta_{0}$ & 3,66 & 0,0010480 & 0,540205 & 2,93182 & 5,15395 \\
\hline$\beta_{1}$ & 0,0433 & 0,1135000 & 0,012392 & 0,01189 & 0,06013 \\
\hline$\beta_{2}$ & $-0,833$ & 0,0000004 & 0,295193 & $-1,73718$ & $-0,49189$ \\
\hline$G$ & 0.752 & 0,0000017 & 0,046690 & 0,67398 & 0,86183 \\
\hline$\sigma_{\eta}^{2}$ & 0,279 & 0,0597000 & 0,035568 & 0,23085 & 0,36763 \\
\hline$\mu_{0}$ & 0,939 & 0,2297000 & 1,246160 & $-0,62805$ & 4,33195 \\
\hline$\sigma_{\omega}^{2}$ & 0,098 & 0,1779000 & 0,004389 & 0,19064 & 0,20823 \\
\hline$\sigma_{\epsilon}^{2}$ & 0,19 & $3,2 \times 10^{-38}$ & 0,009239 & 0,09542 & 0,10449 \\
\hline$\theta$ & 0,00019 & $2,6 \times 10^{-31}$ & 0,000085 & 0,00007 & 0,00049 \\
\hline
\end{tabular}

Pada nilai estimasi kelembaban udara menunjukkan bahwa peningkatan kelembaban di suatu lokasi berkaitan dengan penurunan intensitas hujan di lokasi tersebut. Hal ini sejalan dengan penelitian Nasrullah, dkk [11] yang menunjukkann bahwa kelembaban tinggi cenderung terjadi pada bulan September, Oktober, Maret, Mei, Juli dan Agustus yang merupakan periode musim kemarau. Adapun bulan November, Desember, Januari, April serta Juni merupakan periode waktu terjadinya kelembaban yang rendah dan bersamaan dengan periode musim hujan di Propinsi Sulawesi-Selatan. Berdasarkan Tabel 1 nilai p-value dari uji Shapiro-Wilk terlihat bahwa estimasi parameter $\beta_{1}, \sigma_{\omega}^{2}$ dan $\sigma_{\eta}^{2}$ berasal dari distribusi normal dengan p-value yang lebih besar dari 0,05 .
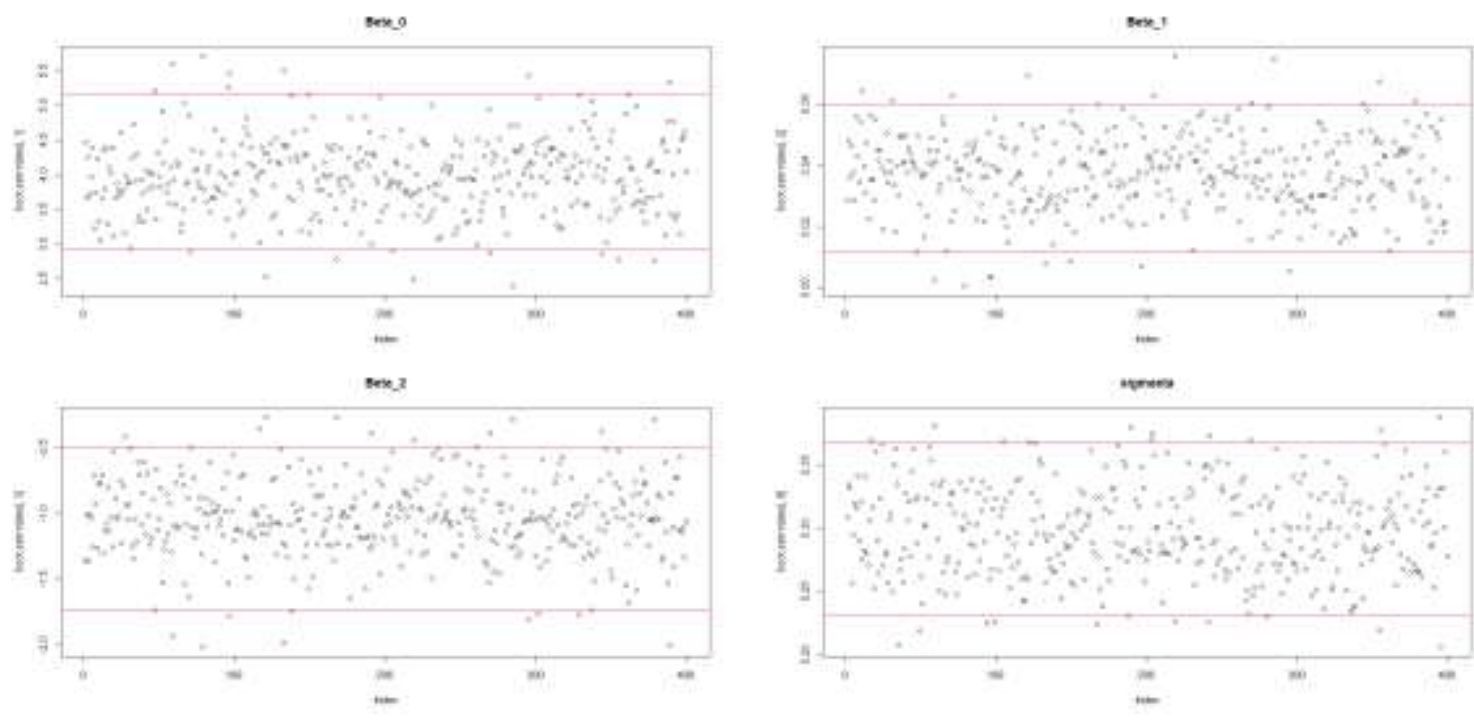

Gambar 2: Plot parameter bootstrap 
Muh. Idil Islami, Amran Rahim, A. Kresna Jaya, Bambang Bakri Jurnal Matematika, Statistika E Komputasi

Gambar 2 menunjukkan bahwa prosedur pembangkitan sampel dengan metode bootstrap untuk setiap parameter model menunjukkan bahwa asumsi distribusi normal dipenuhi. Hal tersebut ditunjukkan dengan hasil uji Shapiro-Wilks yang ditampilkan pada Gambar 3, dimana sebaran sampel setiap parameter dapat dihampiri dengan distribusi normal. Histogram sampel yang dibangkitkan melalui metode Bootstrap berbentuk histogram distribusi normal. Perbandingan sampel dan hasil estimasi parameter yang dinyatakan sebagai titik dalam Gambar 3 menunjukkan bahwa keduanya terletak pada suatu garis lurus. Hal ini menunjukkan bahwa asumsi distribusi normal dapat dipenuhi.
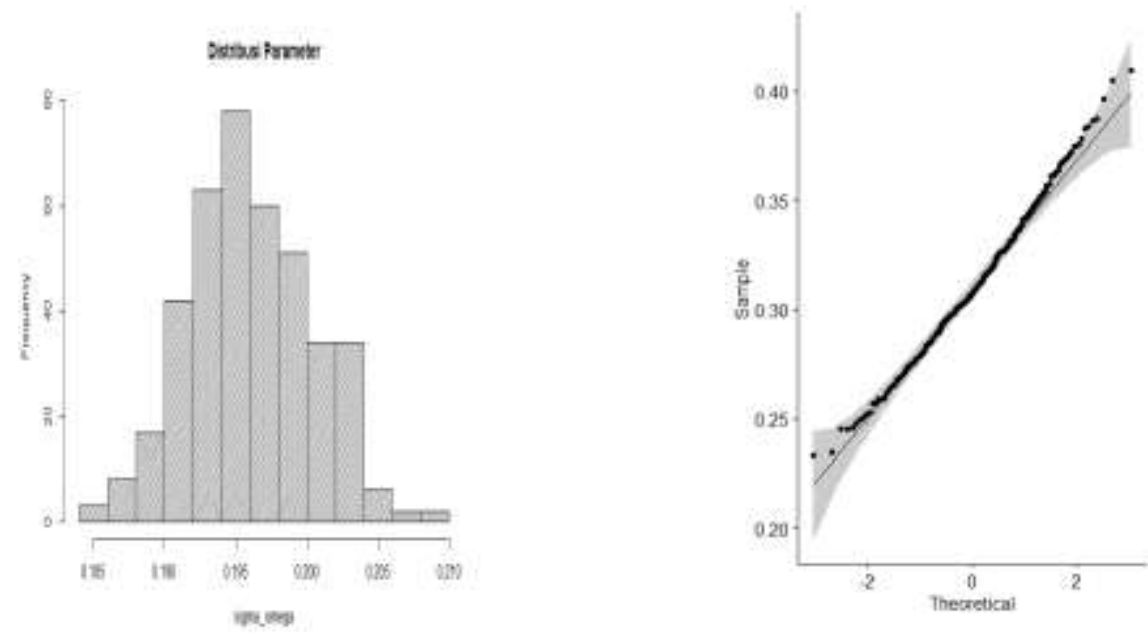

$\sigma_{\omega}^{2}$
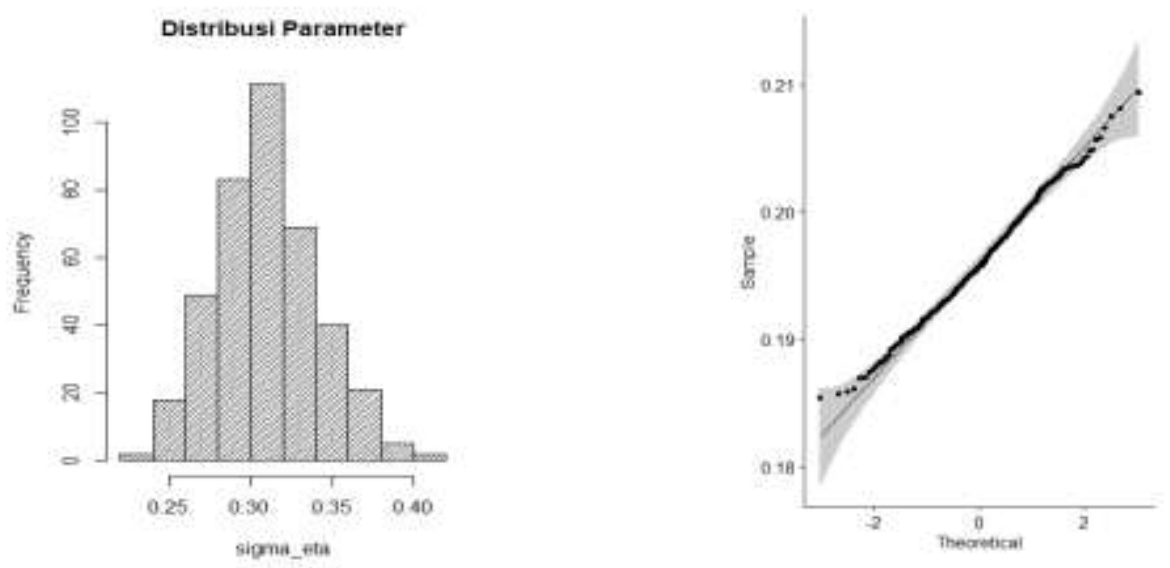

$$
\sigma_{\eta}^{2}
$$

Gambar 3: QQ Plot distribusi parameter $\sigma_{\omega}^{2}$ dan $\sigma_{\eta}^{2}$ 


\section{Muh. Idil Islami, Amran Rahim, A. Kresna Jaya, Bambang Bakri Jurnal Matematika, Statistika \& Komputasi}

\section{KESIMPULAN}

Pemodelan data ST menggunakan model Kalman Filter dengan metode estimasi EM dan metode bootstrap telah digunakan dalam penelitian ini. Hasil penelitian menunjukkan bahwa penggunaan metode bootstrap dapat menghasilkan interval kepercayaan dari estimasi parameter menggunakan metode EM. Hal ini dapat membantu menghitung ukuran ketidakpastian penaksiran parameter. Implementasi model ST pada data curah hujan Provinsi Sulawesi Selatan menunjukkan penggunaan metode Kalman Filter dan metode Bootstrap dapat memberikan hasil yang cukup baik. bahwa terdapat hubungan antara curah hujan, temperatur, dan kelembaban udara. Intensitas curah hujan tinggi akan meningkat seiring dengan peningkatan suhu. Pergerakan angin ke daerah yang bersuhu tinggi dapat membawa kumpulan awan yang menyebabkan intensitas curah hujan di daerah tersebut menjadi meningkat.

\section{DAFTAR PUSTAKA}

[1] Amran, Nur Iriawan, Subiono, Irhamah., 2011. Model Bayesian Hirarki SpatioTemporal Nonstasioner Berbasis Kopula. Surabaya: Institut Teknologi Sepuluh November.

[2] Bilmes, J. A., 1998. A Gentle Tutorial of the EM Algorithm and its Application to Parameter Estimation for Gaussian Mixture and Hidden Markov Models. Retrieved November 2, 2016, from http://www.melodi.ee.washingto.edu/people/bilmes/mypapers/em.pdf

[3] Bilonick, R.A., 1983. Risk qualified maps of hidrogen ion contentration for the New York Stat area for 1966-1978. Atmospheric Environment, 2513-2524.

[4] Cressie, N. A., 1993. Statistics for Spatial Data. New York: John Wiley \& Sons.

[5] Cressie, N., \& Wikle, C., 2002. Space-time kalman filter. Encyclopedia of environmetrics, 2045-2049.

[6] Durbin, J., \& Koopman, S., 2001. Time series analysis by state space methods. New York: Oxford University Press.

[7] Efron, B., \& J. Tibshirani, R., 1993. An Introduction to the Bootstrap. Washington: Chapman \& Hall/Crc.

[8] Fasso, A., \& Cameletti, M., 2017. A general spatio-temporal model for environmental data. Bergamo: GRASPA.

[9] Kharis, M. N., 2014. Analisis Peramalan Pendaftaran Siswa Baru Menggunakan Metode Seasonal ARIMA dan Metode Dekomposisi. Jakarta: Universitas Islam Negeri Syarif Hidayatullah.

[10] Mardia, K. A., 1993. Spatial-temporal analysis of mulitvariate environmental monitoring data. Multivariate Environmental Statistics, 347-386.

[11] Nasrullah, Ramli R., Baharuddin, Rosady M., Nurul J., Asniawaty K., 2015. Temperatur dan Kelembaban Relatif Udara Outdoor. Prosiding Temu Ilmiah IPLBI, D045-D050.

Pfeiffer, D., 2008. Spatial Analysis in Epidemiologi. New York: Oxford University

[12] Press.

[13] Shumway, R. H., \& Stoffer, D. S., 1982. An approach to time series smoothing and forecasting using the EM algorithm. Journal of Time Series Analysis, Wiley Blackwell, 253-264.

[14] Vazquez, A., \& Syversveen, A., 2006. The Ensemble Kalman Filter. Norwegia: Norsk Regnesentral. 
Muh. Idil Islami, Amran Rahim, A. Kresna Jaya, Bambang Bakri Jurnal Matematika, Statistika \& Komputasi

[15] Welling, M., 2010. The Kalman Filter. California: California Institure of Technology.

[16] Wuryandari, T. D., 2014. Identifikasi Autokorelasi Spasial pada Jumlah Pengangguran di Jawa Tengah menggunakan Indeks Moran. Media Statistika, 1-10.

[17] Zucchini, W., \& Mac Donald, I., 2009. Hidden Markov Models for Time Series-an Introduction Using R. London: Chapman \& Hall. 